\title{
Frontières
}

\section{Comment des médecins belges se situent par rapport à l'euthanasie?}

\section{Marie-Luce Delfosse}

Volume 24, numéro 1-2, automne 2011, printemps 2012

L’aide médicale à mourir

URI : https://id.erudit.org/iderudit/1013089ar

DOI : https://doi.org/10.7202/1013089ar

Aller au sommaire du numéro

Éditeur(s)

Université du Québec à Montréal

ISSN

1916-0976 (numérique)

Découvrir la revue

Citer ce document

Delfosse, M.-L. (2011). Comment des médecins belges se situent par rapport à

l'euthanasie ? Frontières, 24(1-2), 88-88. https://doi.org/10.7202/1013089ar d'utilisation que vous pouvez consulter en ligne.

https://apropos.erudit.org/fr/usagers/politique-dutilisation/ 


\section{COMMENT \\ DES MÉDECINS BELGES \\ SE SITUENT PAR RAPPORT À L'EUTHANASIE ?}

Marie-Luce Delfosse, Ph. D., professeure d'éthique et de bioéthique, Facultés universitaires Notre-Dame de la Paix, Namur (Belgique).

Trois médecins belges livrent ici leurs réflexions sur l'euthanasie, chacun à partir de sa pratique professionnelle: médecine générale, maison de repos et de soins, soins palliatifs. Quelles que soient leurs convictions religieuses ou philosophiques, leur cheminement personnel et professionnel les a tous les trois convaincus du bienfondé de la loi belge relative à l'euthanasie et de celui de la possibilité qui leur est ainsi donnée de pratiquer, sous conditions, cet acte. Qu'ils partagent la même conviction ne permet évidemment pas d'inférer qu'il en est de même pour tous les médecins belges. La loi belge prévoit et encadre l'objection de conscience du médecin. Cependant, les réflexions qu'on peut lire ici - et qui sont fortement arrimées à l'expérience et à la pratique - permettent de se rendre compte de façon nuancée de l'articulation de la possibilité ouverte par la loi avec une conscience professionnelle et personnelle exigeante. Dans la mesure où l'euthanasie pose question et n'est légalement admise que dans peu de pays, il m'a paru plus stimulant pour le débat de ne livrer ici que des positions favorables à l'euthanasie. 